\title{
Seawater aluminium seasonal dynamics and response to short-term perturbations in the Gulf of Aqaba, northern Red Sea
}

\author{
TAL BENALTABET, GIL LAPID SR. AND PROF. ADI \\ TORFSTEIN
}

Hebrew University of Jerusalem

Presenting Author: tal.benaltabet@mail.huji.ac.il

Seawater aluminium (Al) is a widely used proxy for atmospheric deposition to surface waters and recycling of terrigenous material in open oceans. However, the impact of short-term environmental events, such as dust storms and sediment resuspension, on the oceanic water column composition is poorly constrained due to the typically low sampling temporal resolution in open ocean environments. The Gulf of Aqaba (GoA), northern Red Sea, is a deep oligotrophic water body, which undergoes seasonal cycles of water column stratification and deep mixing. In addition, the GoA is surrounded by hyperarid deserts with no major tributaries, and hence receives limited terrigenous input, except for frequent dust storms and rare flash floods.

Here, we report a highly resolved time series of vertical profiles of dissolved Al concentrations sampled during 2017 2018, with an emphasis on daily resolution sampling across dust storms and sediment resuspension events. We further evaluate the results in the context of the water column configuration, dissolved Silica ( $\mathrm{Si}$ ) contents, and settling particle fluxes.

Dissolved Al concentrations range between $22-91 \mathrm{nmol} \mathrm{kg}^{-1}$. Upper mixed layer Al inventories display a decrease of up to $20 \%$ in response to dust storms, as dissolved $\mathrm{Al}$ is scavenged onto settling dust particles. By contrast, following a rare wet dust deposition event, $\mathrm{Al}$ inventories in the mixed layer increased by $35 \%$, reflecting the enhanced leaching of mineral Al into the dissolved phase by rainwater.

In response to rapid winter deepening of the mixed layer coupled with an independently observed discrete surge in resuspended particulate material, the water column Al inventory decreased by $26 \%$, demonstrating the short-term effects of $\mathrm{Al}$ scavenging by resuspended material. However, deep Al concentrations are generally elevated during winter, reflecting the long-term contribution of resuspended sediments to the deep Al pool.

In the deep waters, dissolved $\mathrm{Al}$ and $\mathrm{Si}$ display a positive linear correlation while the upper mixed layer $\mathrm{Al} / \mathrm{Si}$ ratio changes seasonally and in response to short-term perturbation. In turn, these observations are used to evaluate the relative role of atmospheric deposition, scavenging and incorporation into diatom frustules and their subsequent remineralization in determining dissolved $\mathrm{Al}$ marine inventories. 